\title{
Covid-19: control measures must be equitable and inclusive
}

\author{
Failure to respect the needs of vulnerable groups will seriously undermine response efforts
}

\author{
Zackary D Berger associate professor ${ }^{1}$, Nicholas G Evans assistant professor ${ }^{2}$, Alexandra L Phelan \\ adjunct professor ${ }^{3}$, Ross D Silverman professor ${ }^{4}$
}

\begin{abstract}
'Johns Hopkins School of Medicine and Johns Hopkins Berman Institute of Bioethics, Baltimore, USA; ${ }^{2}$ University of Massachusetts Lowell, USA; ${ }^{3}$ Georgetown University, Washington, DC, USA; ${ }^{4}$ Richard M Fairbanks School of Public Health and Robert H McKinney School of Law, Indiana University, Indianapolis, USA; Correspondence to: Z Berger zberger1@jhmi.edu
\end{abstract}

The global spread of covid-19 has generated aggressive medical and public health responses, including testing, screening, contact tracing, social distancing, travel restrictions, and orders to stay at home when sick or exposed. ${ }^{1}$ Yet many members of society have reason to distrust public health systems. Containment, mitigation, and suppression plans must be as inclusive as possible or risk undermining response efforts. A commitment to inclusion means responding to covid-19 in a way that is sensitive to our most vulnerable communities, including homeless people, those without adequate insurance or employment, communities of colour, indigenous communities, immigrant communities, people with disabilities, and certain frontline healthcare workers and emergency responders.

Trust begins with communication, and communicating information during outbreaks is challenging, especially as our knowledge of a disease evolves. ${ }^{2}$ Inclusive messaging should be tailored and available in a variety of languages, including sign languages. Honest, transparent communication is vital; confusing or contradictory health messaging engenders mistrust and leads people to seek information from unreliable alternative sources. Underserved communities are rightly distrustful of public health institutions: communities of colour and people with disabilities have historically been undertreated or abused through the medical system, ${ }^{3}$ and undocumented immigrants fear punitive measures should they present at a clinic or hospital. ${ }^{4}$

\section{Free testing}

Next, governments and healthcare systems should provide care to patients without adequate access to health services or insurance benefits-for covid-19 and existing medical conditions. Relying on emergency and acute care settings to care for uninsured people is inefficient, expensive, risks the spread of covid-19, and may cause those at risk to avoid care. Free testing for covid-19 is essential: in countries with fee-for-service healthcare, programmes like the disaster relief Medicaid programme used by New York after 11 September $2001^{5}$ should be implemented- streamlining applications and omitting citizenship requirements to ensure coverage.
Fair and equitable sharing of health resources mitigates further risks to the public's health by meeting community health needs and generates all important trust. Individuals with ambiguous citizenship rights, regardless of their legal status, should be offered care, to encourage them to report when they are ill and stop the spread of covid- 19 .

As governments and institutions implement social distancing measures, including closures and stopping mass gatherings, they must mitigate the effects of these measures on vulnerable communities. School and university closures disproportionately affect vulnerable groups, ${ }^{6}$ in particular students with disabilities and those reliant on their educational institution for food, shelter, residency, and safety. ${ }^{7}$ Any institution closing physical locations must articulate plans for accommodating marginalised groups, ideally with input from representatives from such groups. ${ }^{8}$ Frontline community organisations working with anyone experiencing food, medication, and housing insecurity should receive additional government support.

\section{Employment rights}

Many places are encouraging or requiring people potentially exposed to covid-19 to stay at home for 14 days. It is too demanding, however, to expect individuals to act in the interest of communal health at the expense of their need to work to support themselves and their families. Employment rights, including paid sick leave policies, vary across countries in the Organisation for Economic Cooperation and Development and between different types of employees and workers. ${ }^{9}$

During influenza outbreaks, paid sick leave policies could lower influenza infection rates by up to $40 \% .^{10}$ Healthcare institutions should set the standard by guaranteeing paid sick leave for all employees. Governments should reimburse sick leave expenses for the healthcare enterprises counted on to respond to covid-19 and implement similar programmes to support casual, small business, and gig economy workforces.

Prisons, nursing homes, homeless shelters, and refugee camps can become focuses for disease outbreaks; people in such settings often have inadequate access to basic healthcare and comorbidities that increase the risk of serious illness if they 
develop covid-19. ${ }^{11}$ At the US border, for example, government policies like the "Remain in Mexico" programme can rapidly propagate spread of disease. ${ }^{12}$ Congregate settings should be reconsidered in light of the current situation; if it is deemed critical to maintain them, inhabitants should be provided with testing and care to reduce risk of covid-19 outbreaks.

Responding to the covid-19 crisis physically and mentally strains first responders, clinicians, healthcare workers, and public health practitioners, who often develop the diseases they are treating. ${ }^{13}$ Burnout from exhausting work regimens and increased risks to providers' personal and familial health jeopardises patient health and safety. Vulnerable healthcare support staff (such as cleaners, nursing assistants, and food service workers) warrant explicit protections, including the prioritisation of medical resources and support to ensure continuity of healthcare provision. ${ }^{14}$

The risks of covid-19, like those associated with many acute and chronic health conditions, are heterogeneous and may disproportionately affect vulnerable populations. Governments, institutions, and healthcare facilities all have a role in enacting policies that respect members of vulnerable communities while working towards ending the pandemic. We all hold social and ethical responsibilities to assess and mitigate risks for those groups so often left behind.

Competing interests: We have read and understood BMJ policy on declaration of interests and have no interests to declare.

Provenance and peer review: Commissioned; not externally peer reviewed.
1 Adalja AA, Toner E, Inglesby TV. Priorities for the US health community responding to COVID-19. JAMA 2020. . 10.1001/jama.2020.3413 32125355

2 Childress JF, Faden RR, Gaare RD, etal . Public health ethics: mapping the terrain. $J$ Law Med Ethics 2002;30:170-8. 10.1111/j.1748-720X.2002.tb00384.x 12066595

3 Washington H. Medical apartheid. Doubleday Books, 2005.

4 Bergstresser SM. Health communication, public mistrust, and the politics of "rationality". Am J Bioeth 2015;15:57-9. 10.1080/15265161.2015.1009570 25856606

5 New York State Department of Health. Disaster relief Medicaid evaluation project. 2005. https://www.health.ny.gov/health_care/medicaid/related/docs/drm_report.pdf

6 Berkman BE. Mitigating pandemic influenza: the ethics of implementing a school closure policy. J Public Health Manag Pract 2008;14:372-8. 10.1097/01.PHH.0000324566.72533.0b 18552649

7 Baylis F, Kenny N, Sherwin S. A relational account of public health ethics. Public Health Ethics 2008:1:196-209. 10.1093/phe/phn025.

8 Raub A, Chung P, Batra P, etal . Paid leave for personal illness: a detailed look at approaches across OECD countries. World Policy Analysis Center, 2018.

9 Pichler F, Ziebarth NR. The pros and cons of sick pay schemes: Contagious presenteeism and noncontagious absenteeism behavior. Vox 2018 May 12. https://voxeu.org/article/ pros-and-cons-sick-pay

10 US CDC. Interim US quidance for risk assessment and public health management of persons with potential coronavirus disease 2019 (COVID-19). Exposure in travel-associated or community settings. 8 Feb 2020. https://www.cdc.gov/coronavirus/2019-ncov/php/riskassessment.html

11 Narea N. The fate of Trump's policy of sending migrants back to Mexico now rests with the Supreme Court. Vox 2020 Mar 5. https://www.vox.com/2020/2/28/20907053/remainin-mexico-mpp-ninth-circuit-opinion

12 Habibi R, Burci GL, de Campos TC, etal . Do not violate the International Health Regulations during the COVID-19 outbreak. Lancet 2020;395:664-6. 10.1016/S0140-6736(20)30373-1 32061311

13 Toner E, Waldhorn R. What US hospitals should do now to prepare for a COVID-19 pandemic. Clinicians Biosecurity News, 27 Feb 2020. http://www.centerforhealthsecurity. org/cbn/2020/cbnreport-02272020.html

14 Reid L. Diminishing returns? Risk and the duty to care in the SARS epidemic. Bioethics 2005;19:348-61. 10.1111/j.1467-8519.2005.00448.x 16222844

Published by the BMJ Publishing Group Limited. For permission to use (where not already granted under a licence) please go to http://group.bmj.com/group/rights-licensing/ permissions 